\title{
Synaptic scaling generically stabilizes circuit connectivity
}

\author{
Christian Tetzlaff ${ }^{1,2,4^{*}}$, Christoph Kolodziejski ${ }^{1,3,4}$, Marc Timme ${ }^{1,3,4}$, Florentin Wörgötter ${ }^{2,4}$ \\ From Twentieth Annual Computational Neuroscience Meeting: CNS*2011 \\ Stockholm, Sweden. 23-28 July 2011
}

Neural systems regulate synaptic plasticity avoiding overly strong growth or shrinkage of the connections, thereby keeping the circuit architecture operational. Accordingly, several experimental studies have shown that synaptic weights increase only in direct relation to their current value, resulting in reduced growth for stronger synapses [1]. It is, however, difficult to extract from these studies unequivocal evidence about the underlying biophysical mechanisms that control weight growth.

The theoretical neurosciences have addressed this problem by exploring mechanisms for synaptic weight change that contain limiting factors to regulate growth [2]. The effectiveness of these mechanisms is difficult to justify from a biophysical perspective, in particular those that require knowledge of global network status (e.g. knowledge of the 'sum of all weights') for normalization. Also spike-timing-dependent plasticity [3] cannot guaranty stability because various types of plasticity exist across different neurons and even at the same neuron, depending on the location of the synapses [1].

Therefore, it remains an open question how neural circuits simultaneously stabilize their many synapses and ensure diversity in the presence of a variety of distinct plasticity mechanisms.

In 1998, a series of studies initiated by Turrigiano augmented this discussion by demonstrating that network activity is homeostatically regulated, suggesting that weights $\omega$ are regulated by an activity-dependent difference term $[4,5]$. Accordingly, synaptic scaling compares output activity $v$ against a desired target activity $v_{T}$ of each individual neuron [5]. Most straightforwardly, such a local weight change is defined by $d \omega / d t=\gamma H\left(v_{T}-v\right)$ [6], where the long characteristic time scale (hours up to days) of

\footnotetext{
* Correspondence: tetzlaff@physik3.gwdg.de

${ }^{1}$ Network Dynamics Group, Max Planck Institute for Dynamics and Self-

Organization, 37073, Göttingen, Niedersachsen, Germany

Full list of author information is available at the end of the article
}

synaptic scaling is determined by a small factor $\gamma<<1$. Synaptic scaling operates in parallel to conventional plasticity and acts simultaneously on different synapses. Here we suggest that synaptic scaling is combined with different types of plasticity mechanisms in the same circuit or even at the same neuron and regulates synaptic diversity across the circuit.

We demonstrate that it robustly yields stable and diverse weight distributions which moreover are independent of the individual plasticity mechanism. As scaling co-acts with plasticity, such a combined mechanism is mathematically characterized by a weight change $d \omega /$ $d t=\mu G+\gamma H$. Here $\mu$ defines the rate of change of conventional synaptic plasticity, $\gamma<<\mu<1$, and $G$ and $H$ describe the specific types of plasticity and scaling, respectively [7]. For example, $G$ is different for plain Hebbian plasticity than for STDP. As we show, combining any type of conventional plasticity $G$ with nonlinear weight-dependent scaling $H$ naturally yields global synaptic stabilization across the circuit regardless of the specific form of the plasticity $G$ and also largely independent of the intrinsic neuron dynamics. Our study demonstrates that synapses are stabilized strictly in an input-determined way thereby capturing characteristic features of the inputs to the network. As an important result, we show that such systems are capable of representing a given input pattern via stably changed weights along several stages of signal propagation. This holds even in circuits containing a substantial number of random recurrent connections but no particular additional architecture.

\footnotetext{
Author details

${ }^{1}$ Network Dynamics Group, Max Planck Institute for Dynamics and SelfOrganization, 37073, Göttingen, Niedersachsen, Germany. ${ }^{2}$ Institute for Physics III - Biophysics, Georg-August University, 37077, Göttingen, Niedersachsen, Germany. Institute for Physics, Nonlinear Dynamics, GeorgAugust University, 37077, Göttingen, Niedersachsen, Germany. ${ }^{4}$ Bernstein
} 
Center for Computational Neuroscience, 37073, Göttingen, Niedesachsen, Germany.

Published: 18 July 2011

\section{References}

1. Frömke RC, Poo MM, Dan Y: Spike-timing-dependent synaptic plasticity depends on dendritic location. Nature 2005, 434:221-225.

2. Miller KD, McKay DJC: The role of constraints in hebbian learning. Neural Comput 1994, 6:100-126.

3. Markram H, Lübke J, Frotscher M, Sakmann B: Regulation of synaptic efficacy by coincidence of postsynaptic APs and EPSPs. Science 1997, 275:213-215.

4. Turrigiano GG, Leslie KR, Desai NS, Rutherford LC, Nelson SB: Activitydependent scaling of quantal amplitude in neocortical neurons. Nature 1998, 391:892-896.

5. Turrigiano GG, Nelson SB: Homeostatic plasticity in the developing nervous system. Nat. Rev. Neurosci 2004, 5:97-107.

6. Tetzlaff C, Okujeni S, Egert U, Wörgötter F, Butz M: Self-organized criticality in developing neuronal networks. PLoS Comput. Biol 2010, 6(12):e1001013, doi:10.1371/journal.pcbi.1001013.

7. Abbott LF, Nelson SB: Synaptic plasticity: Taming the beast. Nat. Neurosci (Suppl.) 2000, 3:1178-1183.

doi:10.1186/1471-2202-12-S1-P372

Cite this article as: Tetzlaff et al: Synaptic scaling generically stabilizes circuit connectivity. BMC Neuroscience 2011 12(Suppl 1):P372.

\section{Submit your next manuscript to BioMed Central} and take full advantage of:

- Convenient online submission

- Thorough peer review

- No space constraints or color figure charges

- Immediate publication on acceptance

- Inclusion in PubMed, CAS, Scopus and Google Scholar

- Research which is freely available for redistribution

Submit your manuscript at www.biomedcentral.com/submit 